\title{
Prevalence of Filaria Worm Amongprospective Blood Donors Attending a Tertiary Health Institution In Southwestnigeria
}

\author{
T.OJO-BOLA ${ }^{1}$,C.T. OMISAKIN ${ }^{2}$, A.J ESAN ${ }^{2}$, M.F OWOSENI ${ }^{2}$ \\ ${ }^{I}$ Medical Microbiology Department, Federal Medical Centre, Ido-Ekiti, Nigeria \\ ${ }^{2}$ Hematology Department, Federal medical Centre, Ido - Ekiti, Nigeria
}

\begin{abstract}
The prevalence of microfilaria parasite was carried out among prospective blood donors at Federal Medical Centre (FMC) in Ido Ekiti, Nigeria. A total of 863 blood samples were examined for the parasite using microscopic diagnosis method. 22(2.5\%) samples were positive for different species of microfilaria with highest prevalence observed in Loa loa. All the 22 microfilaremia subjects were male donors and were asymptomatic with highest prevalence among the blood group O Rhesus D positive (77.3\%). Age group 21-30 years were more infected with filarial worm. The results therefore indicate that there is possible warning of problematic transfusion filariasis in this study location as there might be misdiagnosis of the parasite among blood donors and this call for the attention of the relevant authority that blood donors should be adequately screened for microfilaria parasite before such blood is transfused to avert its consequences on the recipients, hence the need for the study.
\end{abstract}

Keywords: prevalence, Filarial worm, blood donor

\section{Introduction}

Blood donation/transfusion to a patient is potentially a life saving procedure and the demand forblood has greatly increased over the years. However, the prevalence of parasitic infection especiallyhaemoparasites is a serious case which needs to be addressed, some diseases resulting from theseparasites during transfusion including malaria, trypanosomiasis and filariasis ${ }^{(1,12)}$.Haemoparasites constitute a serious threat to the human race due to the fatality ${ }^{(8)}$. Among which filarial worm had been reported to cause various degree of deformity among the endemic population ${ }^{(5)}$. Filariasis is a parasitic disease that is caused by thread-like nematodes (roundworms) belonging to the superfamily Filarioidea. These are transmitted from host to host by bloodfeeding arthropods, mainly black flies and mosquitoes ${ }^{(4)}$ Eight known filarial nematodes use humans as their definitive hosts and they are divided into three groups according to the niche within the body they occupy:Lymphatic filariasis is caused by the worms Wuchereria bancrofti, Brugia malayi, and Brugia timori. These worms occupy the lymphatic system, including the lymph nodes; in chronic cases, these worms lead to the disease calledelephantiasis.Subcutaneous filariasis is caused by Loa loa (the eye worm), Mansonella streptocerca, and Onchocerca volvulus. These worms occupy the subcutaneous layer of the skin, in the fat layer. $L$. loa causes Loa loa filariasis, while $O$. volvulus causes river blindness. Serous cavity filariasis is caused by the worms Mansonella perstans and Mansonella ozzardi, which occupy the serous cavity of the abdomen.However, in lymphatic filariasis, the larvae travel to the lymphatic vessels, where they grow into adult worms. As adults, the worms can survive and reproduce for up to 7 years. The gradual buildup of worms in the vessels hinders the lymphatic system's ability to fight infection, and causes lymph fluid to collect typically in the arms, legs, breasts, and male genitals leading to swelling and disfigurement ${ }^{(5)}$.The disease does not spread from direct person to person contact. Instead, it is transmitted by the bite of a mosquito. When one of these insects bites someone who is infected, it takes in the parasites along with its meal of blood. The mosquito then passesthose parasites on to thenextperson it bites. Usually, someone must be bitten many times, typically over a long period, to develop symptoms of filariasis ${ }^{(16)}$. Filariasis is considered endemic in tropical and subtropical regions of Asia, Africa, Central and South America, and Pacific Island nations, with more than 120 million people infected and one billion people at risk for infection ${ }^{(13)}$ and approximately 40 million of them have been disabled or disfigured by the disease. Although contracting filariasis is not a risk in the United State, some recent immigrants may have it, and people who have travelled to other countries can countries can contract the disease as well. Missionaries and Peace Corps volunteers are considered to be most at risk ${ }^{(5)}$. Filariasis is considered endemic in 73 countries; 37 of these are in Africa ${ }^{(11)}$. In communities where lymphatic filariasis is endemic, as many as $10 \%$ of women can be afflicted with swollen limbs, and 50\% of men can suffer from mutilating genital symptoms. Filariasis can last a lifetime, and without treatment it can worsen. The disease can lead to permanent disfigurement and damage to the lymphatic system and kidneys, secondary infectons, hardening and thickening of the skin, and sexual and psychological problems. In countries where the disease is common, a serious social stigma often accompanies it ${ }^{(16)}$. There is no vaccine to prevent filariasis, but controlling the populations of blood-sucking insects, especially mosquitoes, can limit the spread of the disease. In some areas where filariasis 
is common, people are treated yearly with preventive medicine to kill any immature worms in their blood (16). The transmission of filarial worm by blood transfusion is a significant problem in the disease endemic regions of the world ${ }^{(9)}$. However, high prevalence of microfilaria in Africa has compounded the problem of blood shortage in blood banks as prospective blood donors positive for microfilaria are automatically excluded from donation ${ }^{(9)}$.The study conducted by Mabayoje etal. (2006) reported about $1.01 \%$ prevalence rate of microfilaria among blood donor with the highest prevalent observed in Masonella perstans. However, since the National institute of Health ${ }^{(10)}$ consensus conference in 1995 requires that every donor blood should be screened for various infections including HIV, Hepatitis B and C, malaria and syphilis ${ }^{(10)}$, this present study was therefore carried out to determine the prevalence of filarialparasitaemia among blood donors with their blood group and establishing the possible risk of transmission of filarial worm to recipients of blood and to determineif our blood bank is operating safely

\section{Study site and population}

\section{Materials And Methods}

A cross sectional study was carried out in Federal Medical Centre (FMC) Ido-Ekiti, Ekiti State, Nigeria among eight hundred and sixty-three randomly selected blood donors at thehospital's blood transfusion laboratory after given their consent between January, 2012 - August,2013.

\section{Blood collection}

About $2 \mathrm{ml}$ of venous blood samples were collected into an Ethylene diamine tetra acetic acid (EDTA) containing bottles for the study, using vein puncture technique as described in Chessbrough (2000), Ochei and Kolkthar (2000).

\section{Blood examination}

Laboratory analysis was carried out by determining the presence of filarial worm in the blood through wet preparation technique and thick smear stained with Giemsa stain as stated by Ochei and Kolkthar(2000) and view under the microscope.

\section{Results}

The prevalence of microfilaria parasite among blood donor at the study site is presented in table 1 . Of the eight hundred and sixty-three blood sample screened, $22(2.5 \%)$ blood were positive for microfilaria. However, all the $22(2.5 \%)$ blood that were positive for microfilaria were all male subjects (Table 2). Participants within age group 21-30 had the highest prevalence of microfilaria while the least was recorded in age group 41-50. None was recorded among age group 11-20 and 51-60 years. There was variation in microfilaria prevalence in blood groups, with the highest prevalence in blood group O Rhesus D positive (77.3\%), followed by A Rhesus D positive (13.6\%), blood group B Rhesus Dpositive and A Rhesus D negative had $4.6 \%$ prevalent. None was recorded among participant with blood group AB Rhesus D positive, B Rhesus D negative, $A B$ rhesus $D$ negative and $O$ rhesus $D$ negative (figure 1).Figure 2 showed the prevalence with microfilaria type. Out of the $22(2.5 \%)$ that were positive for microfilaria; $9(40.9 \%)$ had Loaloa, 6(27.2\%) had Onchocercavolvulus, followed by Mansonellaperstan 5 (22.7\%) while $2(9.1 \%)$ had Wuchereriabancrofti.

Table 1: Overall Prevalence of Microfilaria among blood donor

$$
\text { Frequency (\%) }
$$

Positive $\quad 22.0 \quad(2.5)$

Negative $\quad 841.0 \quad(97.5)$

Total $863.0 \quad(100)$ 
Table 2: Prevalence of Microfilaria in relation to the sex

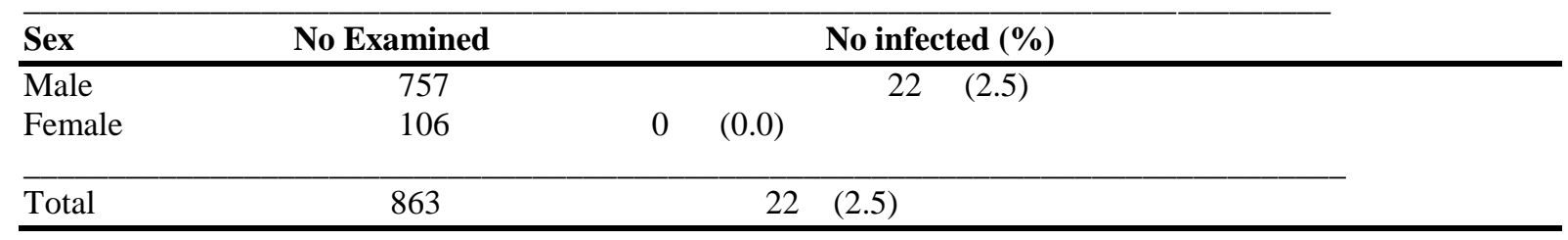

Table 3: Prevalence of Microfilaria in relation to age

\begin{tabular}{lcc}
\hline Age group No examined (\%) & No infected (\%) \\
\hline $11-20$ & 6.0 & $0.0(0.0)$ \\
$21-30$ & 331.0 & $18.0(81.8)$ \\
$31-40$ & 452.0 & $3.0(13.6)$ \\
$41-50$ & 72.0 & $1.0(4.6)$ \\
$51-60$ & 2.0 & $0.0(0.0)$ \\
& & $22.0(100.0)$ \\
\hline Total & 863.0 & 2 \\
\hline
\end{tabular}

Figure 1: Prevalence of Microfilaria in relation to blood group among blood donor

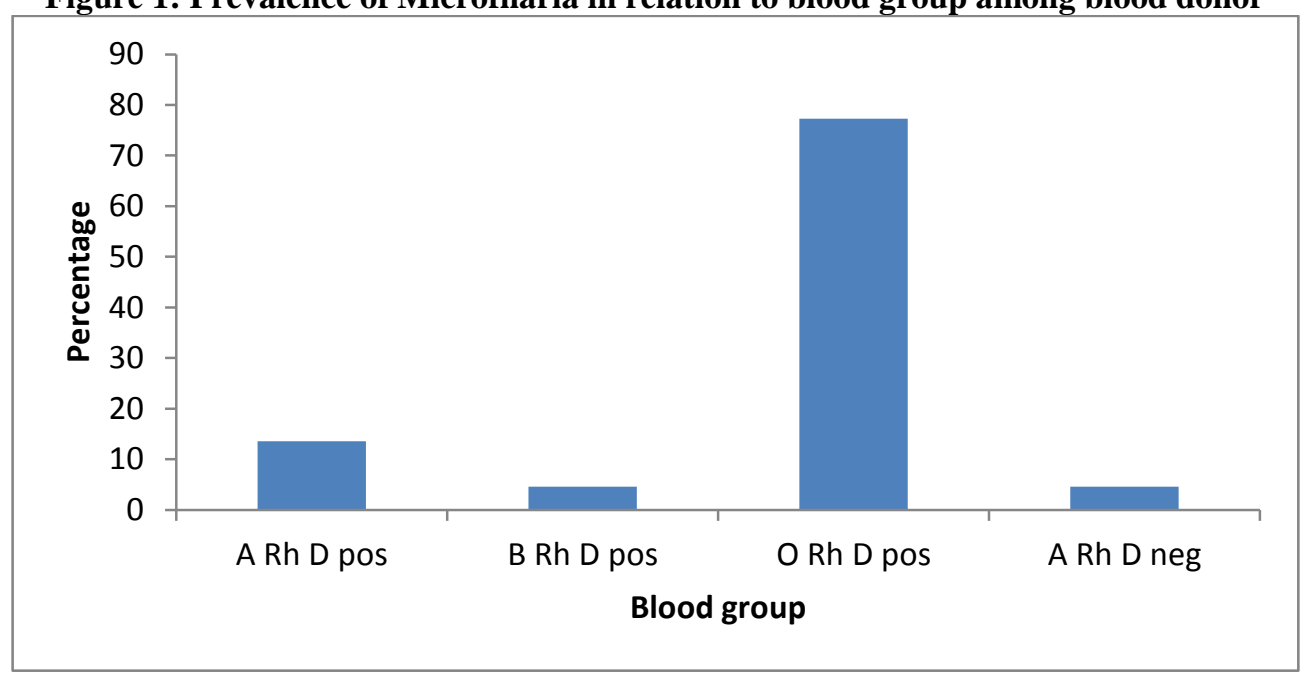

Figure 2: Prevalence with Microfilaria type

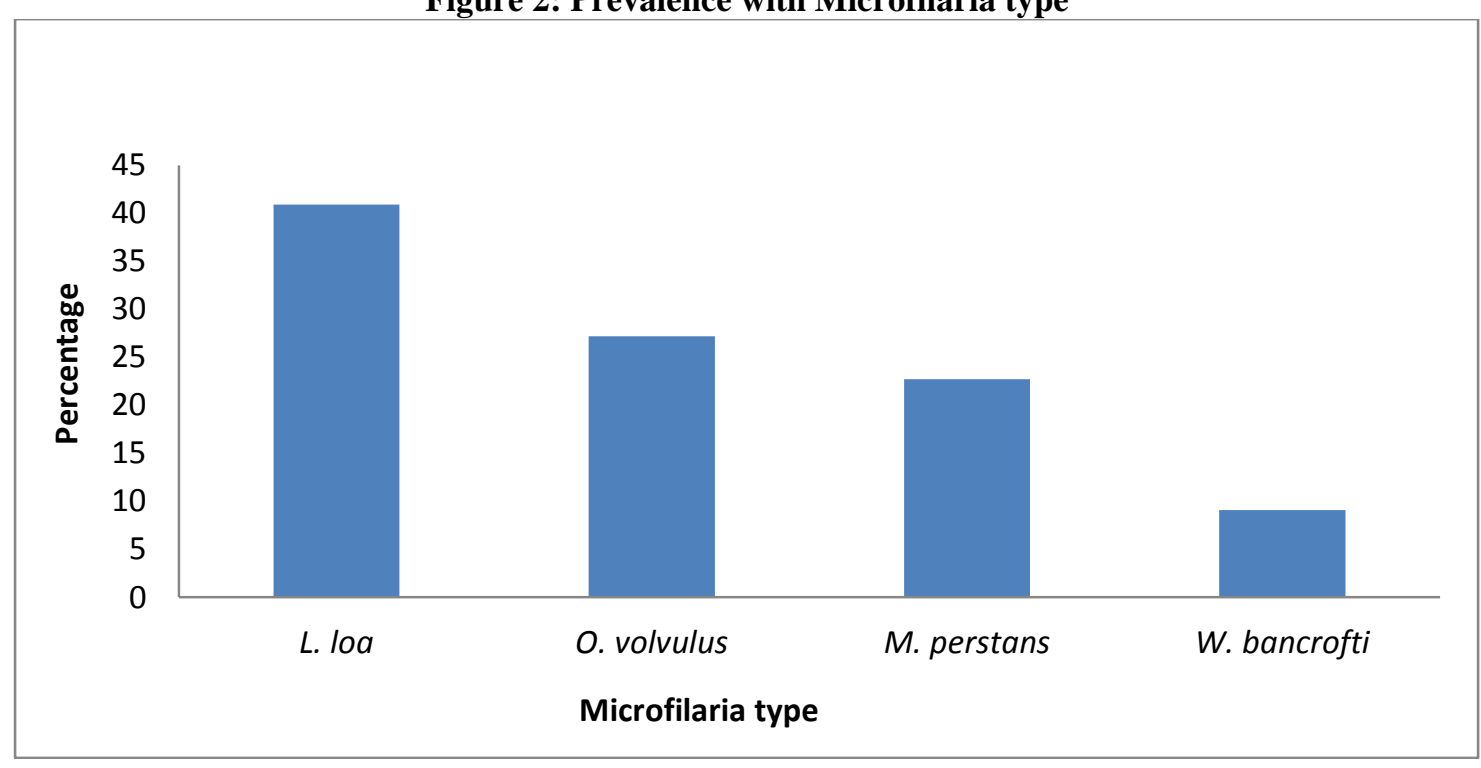




\section{Discussion}

As other blood infections, filarial transfusion-related transmission is possible. However, the result obtained in the present study showed the relatively increase in prevalence of microfilaria infection among blood donor compare to the study conducted by Mabayoje etal. (2006). The implication of this with regard to blood transfusion is paramount and this shows that blood transfusions carry the risk of transmitting microfilaria parasite to the recipients. Although, microfilariatest is among the tests that satisfy the blood safe for transfusion; however, its transmission by blood transfusion is not impossible, but pose a serious threat to the recipient of the blood and reduce the availability of the blood in the blood bank as any donor with microfilaremia will be excluded automatically. Male subjects were only positive for microfilaria among the participant. This might be due to the fact that male subjects are frequently involved in blood donation compare to female subjects who are usually reluctant in donating blood as some of them will complain of monthly menstruation and being a nursing mother. There was variation in microfilaria prevalence among blood group of the donors. The high prevalence among blood was observed among group O Rhesus D positive. This may be due to the fact that the group was the dominant blood group type in blood transfusion science. Loasis are more common among the blood donor in this present study, this agreed with the work of Akinboye and Ogunrinade ${ }^{(2)}$ that reported $11.3 \%$ prevalent of blood parasite among donor with about 3.5\% Loa loa microfilaremia unlike the study conducted by Mabayoje etal. ${ }^{(9)}$ that reported the highest prevalent in Mansonella perstans in Osogbo, Nigeria.

\section{Conclusion}

Transmission of microfilaria by blood transfusion is a significant problem in the disease endemic regions ${ }^{(6)}$ and non endemic region ${ }^{(3,14) .}$ This is because there might be misdiagnosis of the parasite;it then becomes imperative therefore, for the health care provider in transfusion science to be holistic in screening of donor so as to reduce the spread of the parasite and avert its consequences in the recipient.

\section{References}

[1]. Ajayi M.B; Agboola T.F; Adeleke M.A and Gyang P.V (2010). Prevalence of malaria parasite among blood donors in Lagos University teaching hospital, Lagos Nigeria. Annals of Biological Research, 2010, 1 (3):72-75

[2]. Akinboye, DO and Ogunrinade, AF (1987). Malaria and loaisis among blood donors at Ibadan, Nigeria. Trans R Soc Trop Med Hyg. 81:398-9.

[3]. Bregani ER, Balzarini L, Ghiringhelli C and Tarsia P (2003). Transfusional Mansonellaperstans microfilariasis. Parassitologia. 45:71-2.

[4]. Center for Disease Control and Prevention. (2010) "Lymphatic Filariasis"www.cdc.gov

[5]. Centre for Disease and Prevention (CDC)(2011). The CDC provides a fact sheet and other information on filariasis at its website. http://www.cdc.gov.

[6]. Choudhury N; Murthy PK and Chatterjee, RK, (2003). Transmission of filarial infection through blood transfusion. Indian JPatholMicrobiol.;46:367-70.

[7]. Cimo P.L; Luper, W.E; Scouros, M.A (1993). Texas medicine, 89 (12): 48 - 50.

[8]. Eisenman, A; Baruch, T; Schechter, Y; Oren, I (1995). Vox Sanguins,; 68 (i); $19-21$.

[9]. Mabayoje, V.O; Adeyeba, A.O, Taiwo, S.S; Muhibi,MA; Ojurongbe, O.(2006). Prevalence of filariasis among prospective blood donors at Ladoke Akintola University Teaching Hospital, Osogbo, Nigeria. Nigerian Journal of Health and Biomedical Sciences Vol. 5 (2) 2006: 71-73

[10]. NIH (1995). National Institute of Health Consensus Panel on Infectious Disease Testing for blood transfusions. JAMA; 274 (17): $1374-9$

[11]. Ottesen, EA; Hooper PJ; Bradley M and Biswas G (2008),"The Global Programme to Eliminate Lymphatic Filariasis: Health Impact after 8 Years", in De Silva, Nilanthi, PLOS Neglected Tropical Diseases2 (10): e317,

[12]. Ross, M.H; Ruth, E.J. (1985) 'Microfilariasis' Harper and Row Publishers, J. B. Lippin cott company, 298.

[13]. The Carter Center (2002), Summary of the Third Meeting of the International Task Force for Disease Eradication

[14]. Weller PF, Simon HB, Parkhurst BH and Medrek TF (1978). Tourism-acquired Mansonellaozzardi microfilaremial in a regular blood donor. JAMA. ;240:858-9.

[15]. World Health Organization (WHO) (1996). Bulletin of the WHO, 74: $47-54$.

[16]. World Health Organization (WHO) (2011). The WHO tracks disease outbreaks around the world and offers information about filariasis. http://www.who.int 